\title{
A 3D gravity model of crustal structure in the Central-Eastern Alpine sector
}

\author{
Roberto Cassinis, Francesco Federici, Andrea Galmozzi and Salvatore Scarascia \\ Dipartimento di Scienze della Terra, Sezione di Geofisica, Università di Milano, Italy
}

\begin{abstract}
Assuming as a starting model the pattern of the Moho boundary as interpreted in a recent study on the basis of the available DSS profiles, a preliminary 3D gravity model of the crustal structures in the Central-Eastern Alpine sector is proposed. The aim of the present work is to confirm the seismic results concerning the Moho and to better shape the main discontinuities in the intermediate and upper crust, where the seismic data are too scattered to allow a reliable interpretation. The gravity field is calculated along twelve cross-sections oriented $\mathrm{S}-\mathrm{N}$ and crossing the Alpine range from the Padan-Venetian plain to the Bavarian molasse and to the Austrian calcareous Alps. The westernmost section coincides with the European Geotraverse while the easternmost one is positioned at the longitude of about $14^{\circ}$ east. The assumed density model is very simple (only 6 layers); for each unit the density is maintained constant. The model describes a European mantle dipping southwards underneath an overlapping, uplifted Adriatic mantle. As far as the lower crust is concerned, its top is found at depths between 18 and $28 \mathrm{~km}$, the deepest values being reached in the south-eastern sector; the density appears higher in the Adriatic domain than in the European one and the Adriatic lower crust seems to be deeply indented northwards. The low density surface layers appear very thin in a large area of the northwestern sector, while in the south and southeast their thickness reaches about $10 \mathrm{~km}$. This study must be considered as a complement to the seismic interpretation both as a validation of the model of the deep crust and Moho boundary and as an additional source of information on the upper crust.
\end{abstract}

Key words Eastern Alps - gravity modelling deep crust - Moho boundary

\section{Introduction}

A new model of the deep crustal structure in the Central-Eastern Alpine sector was recently proposed (Scarascia and Cassinis, 1997). The construction of this model is based on the reinterpretation of the available DSS (Deep Seismic Soundings) made using homogeneous criteria. Owing to the rather scattered available

Mailing address: Prof. Roberto Cassinis, Dipartimento di Scienze della Terra, Sezione di Geofisica, Università di Milano, Via Cicognara 7, 20129 Milano, Italy; e-mail: cassinis@imiucca.csi.unimi.it seismic data, the interpretation is unable to give detailed information on the shallower geological formations.

The following main conclusions were derived from the seismic study:

- The lower crust and the Moho beneath the Northern Alps show a fairly homogeneous structure: the seismic velocity of the European lower crust is anomalously low. In the north the southward dip of the bottom of the European crust is of about $12^{\circ}$, while in the center of the investigated area it appears to be reduced to about $6^{\circ}$.

- The northern strip of the Adriatic crust appears highly fragmented into small blocks, each block dipping in different directions.

- While the edge of the Adriatic Moho is fairly coincident with the Insubric line in its 
western sector (Tonale line), it appears to be strongly displaced in the eastern one (Pustertal line).

- Also in the Eastern Alps, in agreement with the interpretation of the European Geotraverse (EGT), a wedge (or «indenter») of the Adriatic lower crust overrides the European crust, protruding northwards beyond the edge of the Adriatic Moho.

The gravity field is a complementary source of information on crustal structure. The qualitative studies of gravity anomalies have given the basic ideas on Alpine orogen since the sixties (Berchemer, 1968). Karner and Watts (1983), still on the base of gravity, made a comparison among the recent orogenic ranges and emphasized the meaning of the asymmetry of the anomalies crossing the Alpine chain.

During the different phases of seismic exploration a huge amount of data was gathered, especially in the Western and Central Alpine sectors where deep NVR (Near Vertical Reflection) profiles were recorded. These data can be used as constraints for a quantitative interpretation of the gravity field, employing the techniques of modelling. Therefore gravity models were built, starting from the published Bouguer maps and also using new surveys around the seismic transects (see, among other works, the 2D or 2.5D models by Bayer et al. (1996), for Western Alps; Holliger and Kissling (1992), for Central Alps). While gravity interpretation is ambiguous, the seismic constraints create a model that does not contradict the hypotheses made. Thus, gravity modelling helped to accept a radical change from the previous hypothesis of vertical lithospheric subduction to that of the Adriatic plate overthrusting the European one, while the latter is subducting southwards at a low angle; moreover the existence of a high density lower crust in the axial zone of the orogen was postulated. The models also showed similarities between the crustal structure beneath the Western and Central Alps.

The Eastern Alpine sector is not yet crossed by deep NVR transects. However the assumed seismic model is based on several DSS profiles whose many intersections increase the reliability of the interpretation.
The objective of this study is to verify whether the interpretive hypotheses leading to the seismic model were in contrast with regional gravity anomalies, and to give information on the upper crust, where the seismic constraints are lacking.

Figure 1 is a scheme of the surveyed area: the main geological units and tectonic lines are shown as well as the traces of 12 cross-sections where the 3D gravity models were calculated (see later).

\section{Bouguer regional anomalies}

Figure 2 shows the Bouguer anomalies in the Central-Eastern Alpine sector. They were drawn as a mosaic derived from three maps (Schwerekarte der Schweitz, 1979; Schwerekarte von Österreich, 1965; Gravimetric Map of Italy, 1989) in different scales, based on surveys carried out with different criteria and reference values for the observed gravity. The contour interval is $10 \mathrm{mGal}$. For these reasons the anomalies must only be regarded as regional: local anomalies of wavelength $<15-20 \mathrm{~km}$ cannot be considered reliable. Despite these limitations, the broad pattern of the Bouguer map is a clear indicator of the deep crustal structure. The main features that can be observed at first glance are: the relatively smooth and regular gradient in Northern Alps dipping south towards the axial zone, contrasting with the steep and irregularly directed strips of gradients observed in the southern area, thus suggesting an asymmetrical crustal structure; the two areas of minima beneath the orogen, separated by a shifted saddle just north of the Giudicarie line; the very broad minimum, positioned on Helvetic and Pennidic nappes, sharply contrasting with the eastern negative anomaly, corresponding to the Tauern window, much narrower and elongated, thus suggesting a different structure both of shallow and deep crust; the prevailing positive values and the irregular pattern in the southern area, evidencing a sudden crustal thinning and a complex structure in the Adriatic domain. 


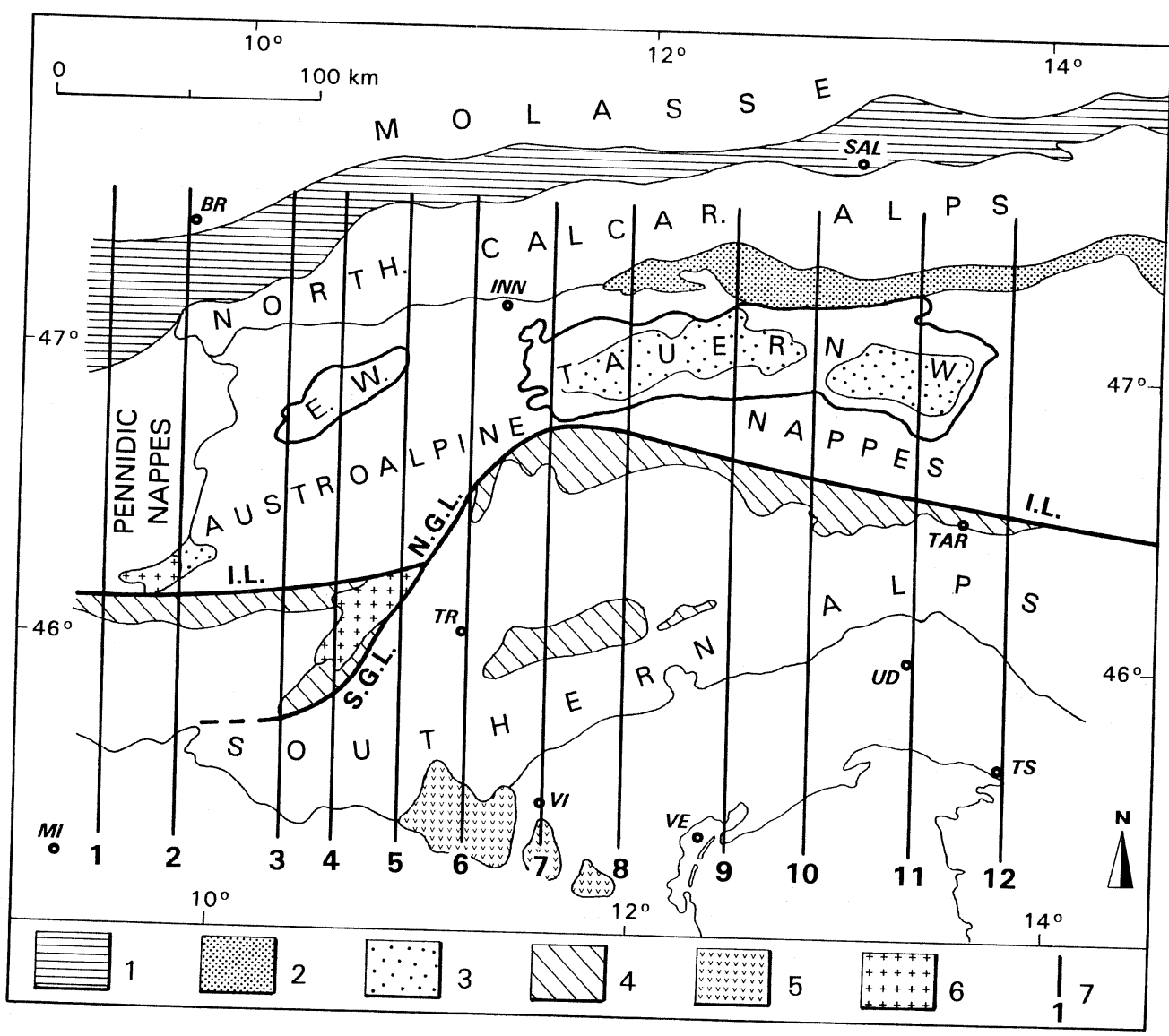

Fig. 1. Scheme of the surveyed area. The main geological units and tectonic lines are shown together with the traces of the 12 interpretive cross sections where the 3D gravity models were calculated. 1) Rhenodanu5) magmatic effusive rocks; 6) Alpine plutons; 7) crystalline Pennidic basement; 4) Southalpine basement; S.G.L. = South Giudicarie line. N.G.L $\mathrm{MI}=$ Milano; $\mathrm{VI}=$ Vicenza; VE = Venice; $\mathrm{TS}=$ Triearie line; E.W. = Engadine window. Cities and towns: $\mathrm{BR}=$ Bregenz; INN = Innsbruck.

\section{Calculation of the 3D model}

The computed Bouguer anomalies given by the assumed model were obtained by means of the IGAS 3D programme (Götze and Lahmeyer, 1988) on twelve parallel cross-sections (figs. 1 and 2). All sections are oriented $\mathrm{N} \rightarrow \mathrm{S}$ and have the same length $(250 \mathrm{~km})$. The average distance between them is of about $30 \mathrm{~km}$. Section 1 roughly corresponds to the stretch of the European Geotraverse (EGT) across the Alpine orogen; section 12 lies near to the meridian $14^{\circ} \mathrm{E}$ crossing the Gailtal line east of Tarvisio, near Villach.

On cross-sections 2 and 7 the calculation was repeated using a 2D approach (programme MAGIX - XL) in order to assess the influence of the non-cylindricity of the structures. A total of 907 observed gravity values was used for the calculation. 


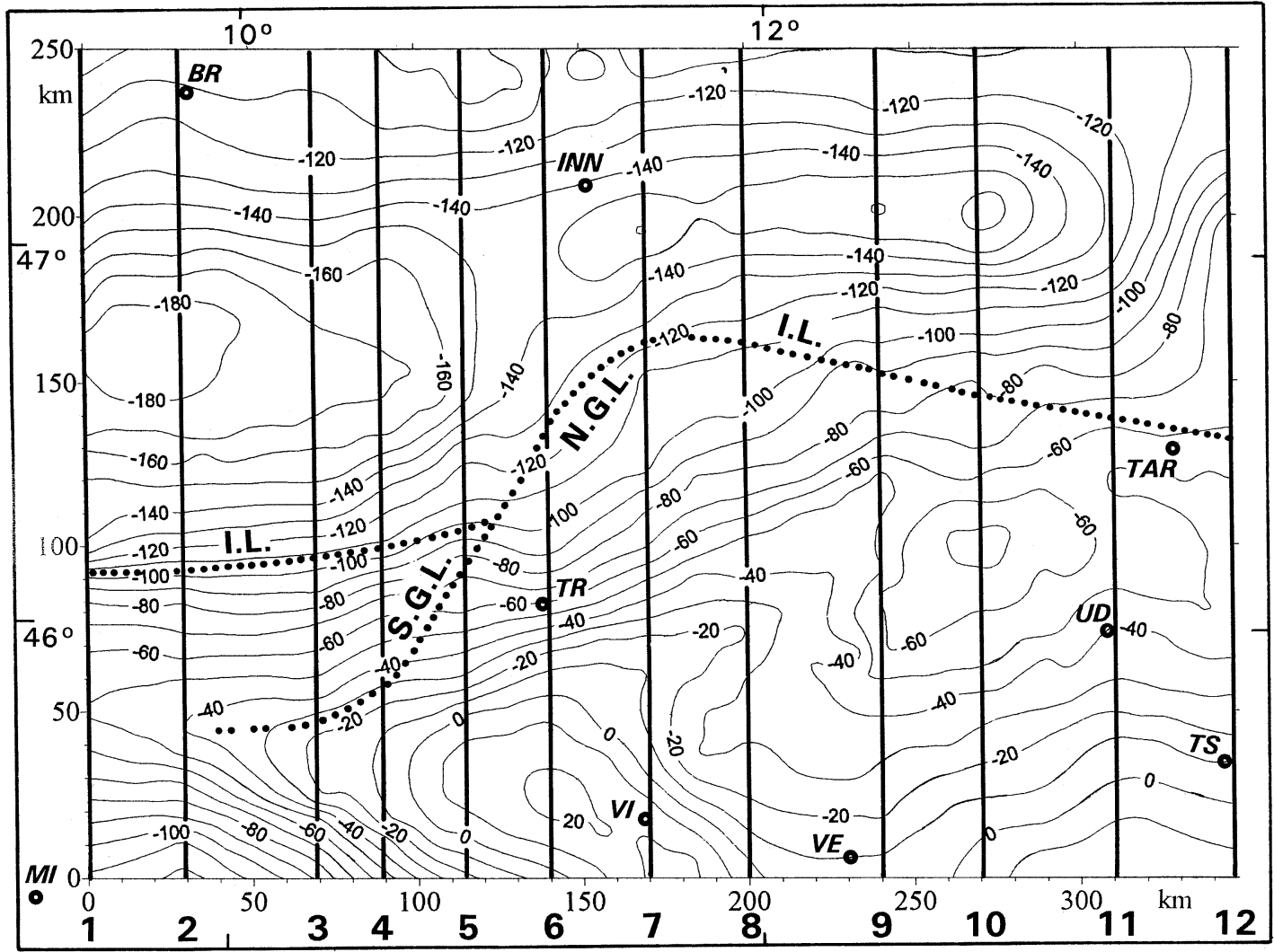

Fig. 2. Map of regional Bouguer anomalies plotted after the Austrian, Italian and Swiss maps. Contour interval $10 \mathrm{mGal}$. The traces of the interpretive cross-sections are also shown. Geographic references as in fig. 1 .

\section{Density model}

Taking into account the regional character of this study, a simplified distribution of the density was adopted. Only 6 values were chosen, corresponding to the same number of bodies, namely (densities $\delta$ in $\mathrm{g} \times \mathrm{cm}^{-3}$ ): 2.3 for shallow sediments (plio-quaternary and molassic basins); 2.55 for the compact rocks of the uppermost crust; 2.7 for the upper crystalline crust; 2.8 for the lower crust of the European domain; 2.95 for the lower crust of the Adriatic domain; 3.3 for the upper mantle. The division of the lower crust into two domains is justified by the seismic interpretation, that gave different velocity values, as recalled earlier. The densities of the other bodies were kept constant over the whole area. The adopted values always fall within the range of the Nafe and Drake (1963) relationships with the observed compressional velocities.

The thickness of the light sediments in the Padan-Venetian plain (southern end of cross sections) was derived from Agip interpretations (Cassano et al., 1986). For the shallow and outcropping geological features in the Alpine area we quote, among other works, those by Castellarin et al. (1992), the cross sections by Röder and Bögel (1978) and, mainly as far as the Tauern window is concerned, those by Lammerer (1996). 


\section{3D gravity models}

Figures 3.1-3.12 illustrate the optimised models. On the top of each figure both the observed and the calculated gravity anomaly along the section are plotted. On the bottom the density model is shown. The geometry of the Moho is taken fundamentally from the seismic interpretation quoted above. The top of the lower crust and of the «crystalline» basement (top of the formation with $\delta=2.7$ ) were partly derived from seismic data, partly from the gravity model itself. The shallow formations were featured upon geological information, and helped by the behaviour of short wavelength anomalies. It must be noted that, especially in the easternmost part of the survey, the seismic data are sparse. Here gravity interpretation is worthwhile to interpolate the data obtained on distant seismic profiles.

In order to briefly describe the models, the cross sections can be better divided into groups. The westernmost of them (sections 1-5) crosses the Central Swiss Alps and the Lombardian Southern Alps. Section 1 roughly corresponds to the EGT, whose results are taken as reference because of the wealth of information gathered there by integrated geophysical methods (Buness, 1992; Ye et al., 1995). All these sections cut the western portion of the Insubric line (Tonale line) at about the same distance from their southern end. Sections 4 and 5 cross the Adamello pluton and the southern sector of the Giudicarie line. The general features of these sections are very similar and suggest a fair cylindricity of deep structures. They exhibit a broad negative anomaly beneath the Alpine axial zone $(-160 \mathrm{mGal})$ and a very pronounced high south of the Tonale line, on the Southern Alps, the positive anomaly increasing eastwards up to lines 5 and 6 where the maximum is found (+20 mGal). The modelling confirms the seismic interpretation in that the southeastern dip of the European Moho is constant on lines 1 and 2, while on lines 3, 4 and 5 it becomes gentler beneath the axial area.

On sections 1 and 2 the largest vertical offset of the Moho boundary is located roughly beneath the flexure of the anomaly curve, while the northern edge reached by the Adriatic «indenter» of the lower crust seems to correspond to the gravity minimum beneath the Alpine range and, therefore, seems to extend northwards beyond the Insubric line. The same situation is found on lines 3, 4 and 5, were the Moho offset appears smaller. The hypothesis of an «indenter» with density higher than the one of the European lower crust beneath the orogen seems suitable to explain the pattern of the anomalies. It must also be remarked that, on sections 1 and 2, the best fit between the calculated and observed anomalies is obtained assuming an uplift of the «crystalline basement» $(\delta=2.7)$ in correspondence of the paleozoic and crystalline outcrops both $\mathrm{N}$ and $\mathrm{S}$ of the Tonale line.

On section 6, that crosses the Northern Giudicarie line (north of Trento), the negative area broadens and the distance between the maximum and the minimum in the axial zone appears increased.

To the east of the Giudicarie line, at the beginning of the Pustertal line, (cross-section 7), the anomaly pattern changes again and is substantially repeated proceeding eastwards, up to section 10. All these sections cross the Tauern window; here the negative minimum is very narrow, exhibiting a striking contrast with the cross sections west of the Giudicarie. Their southern part does not reach the Adriatic foredeep, the anomalies continuing to rise southwards. The overriding front of the Adriatic Moho, marked by the largest vertical offset, is now found about $60 \mathrm{~km}$ south of the Pustertal line; proceeding eastwards, it seems to cross again the Insubric lineament (Gailtal) between sections 9 and 10, thus showing a large unconformity between the shallow and deep structures. The vertical offsets become smaller while going eastwards as well as the crustal thickness, while the «indenter» progressively disappears. The negative area corresponding to the border of the Carnic Alps is also enhanced by the Friulan sedimentary basin.

The narrow area of minimum beneath the Tauern window is attributed both to the shallow lithology and to the tectonic features of the window and also, though to a lesser extent, to the influence of the «indenter» of the lower 

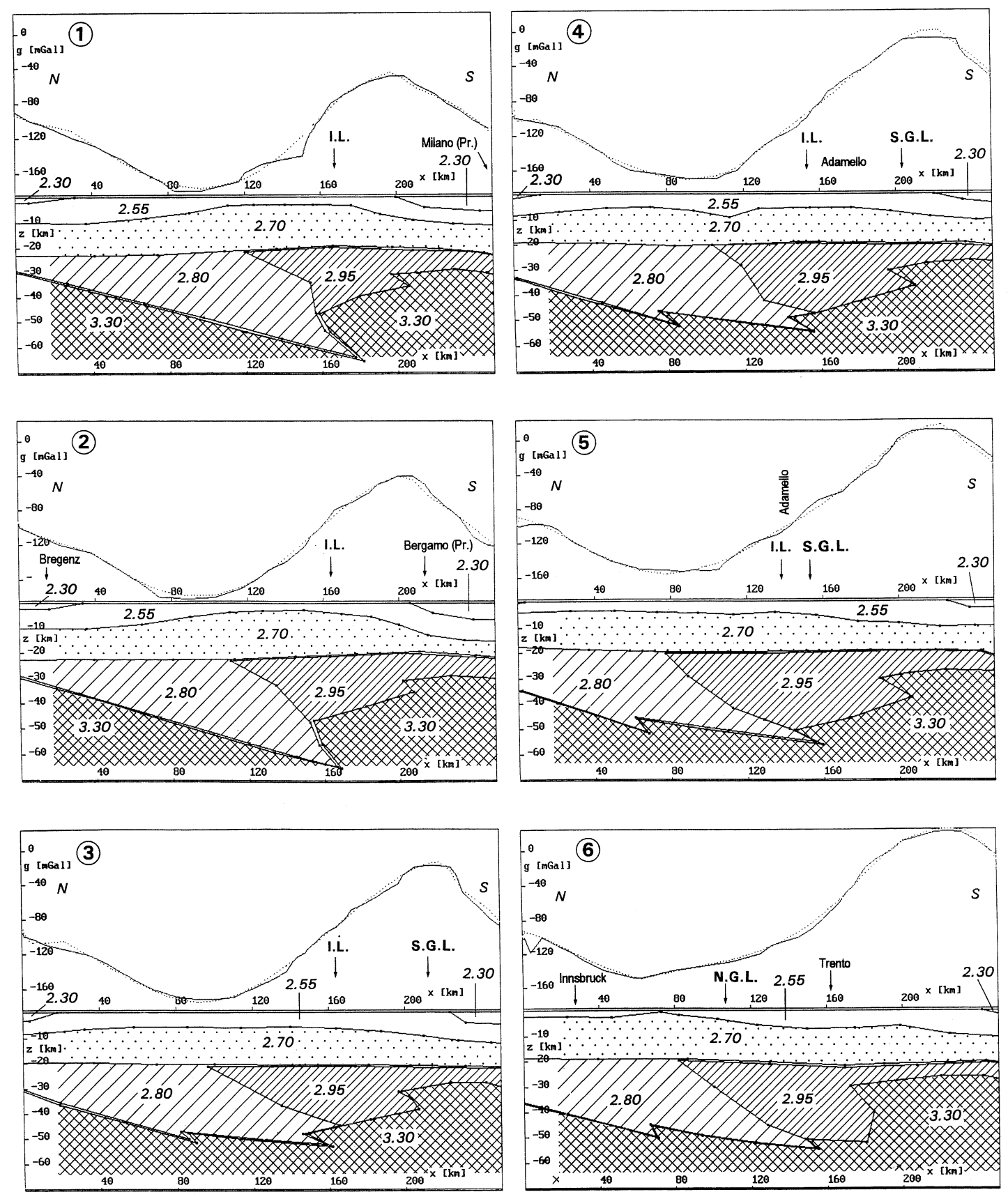

Fig. 3.1-3.12. Gravity models (3D) calculated along the 12 cross sections (see figs. 1 and 2 for location). On top of each model the observed Bouguer anomaly (unbroken line) and the calculated anomaly (dotted line) are shown; on the bottom the optimized density model is described (densities in $\mathrm{g} \times \mathrm{cm}^{-3}$ ). Molassic basins 

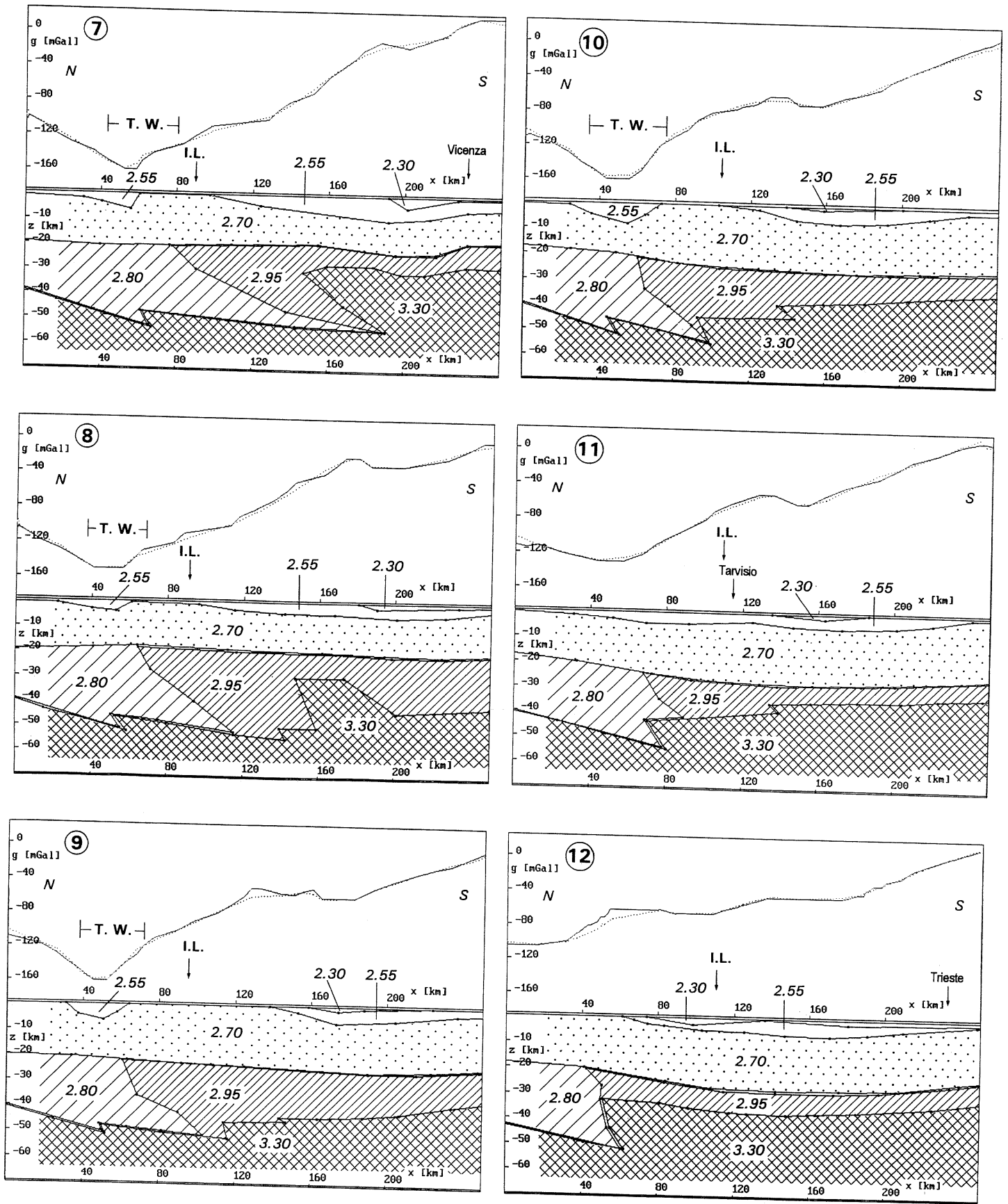

2.3; sedimentary and metamorphic rocks of the upper crust 2.55; crystalline basement and upper crust 2.7; S.G.L. = South Giudicarie line; N.G.L. = North Giudic domain) 2.95; upper mantle 3.3. I.L. = Insubric line; 


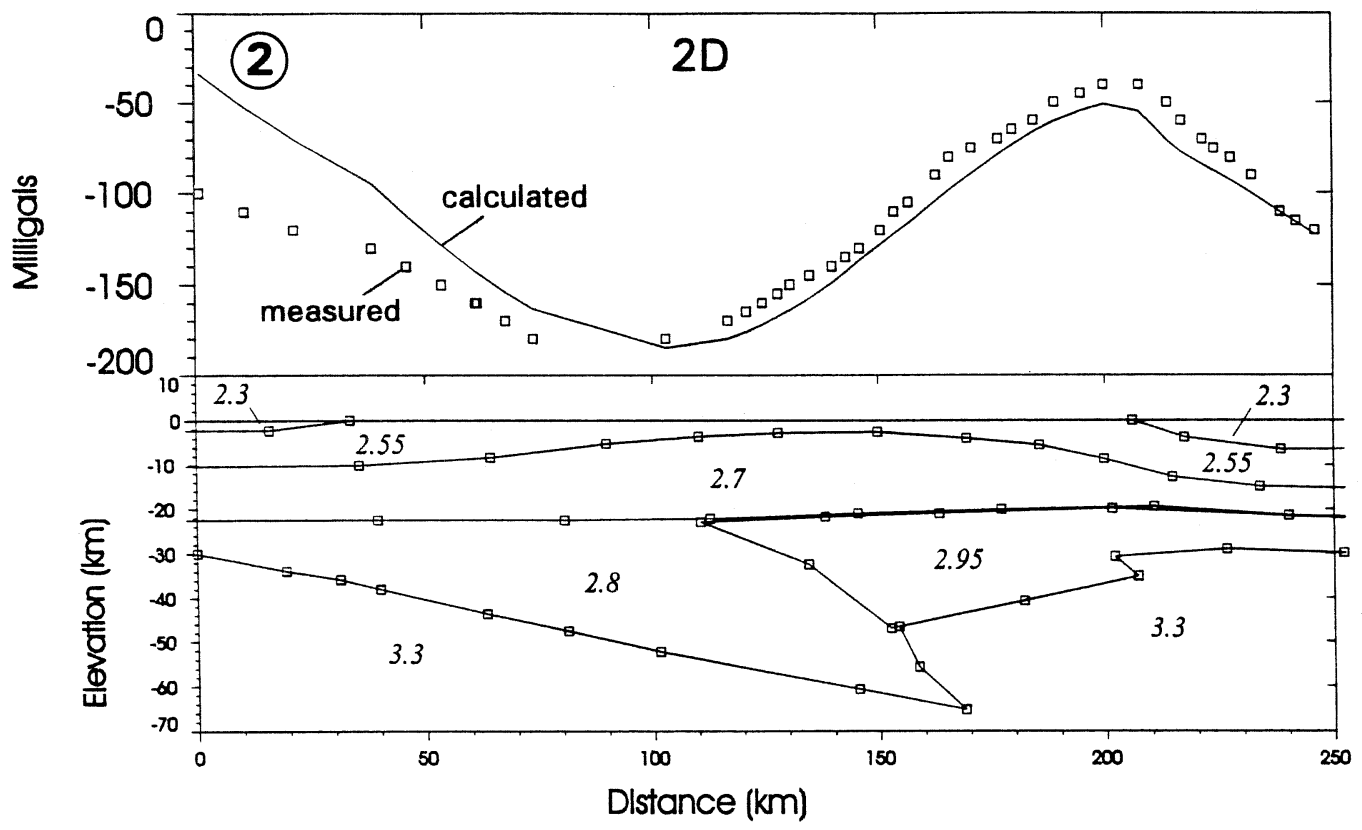

Fig. 4.1 2D gravity model along cross section 2. See fig. 1 and 2 for location and the 3D model of fig. 3.2 for comparison. The density model is unchanged.

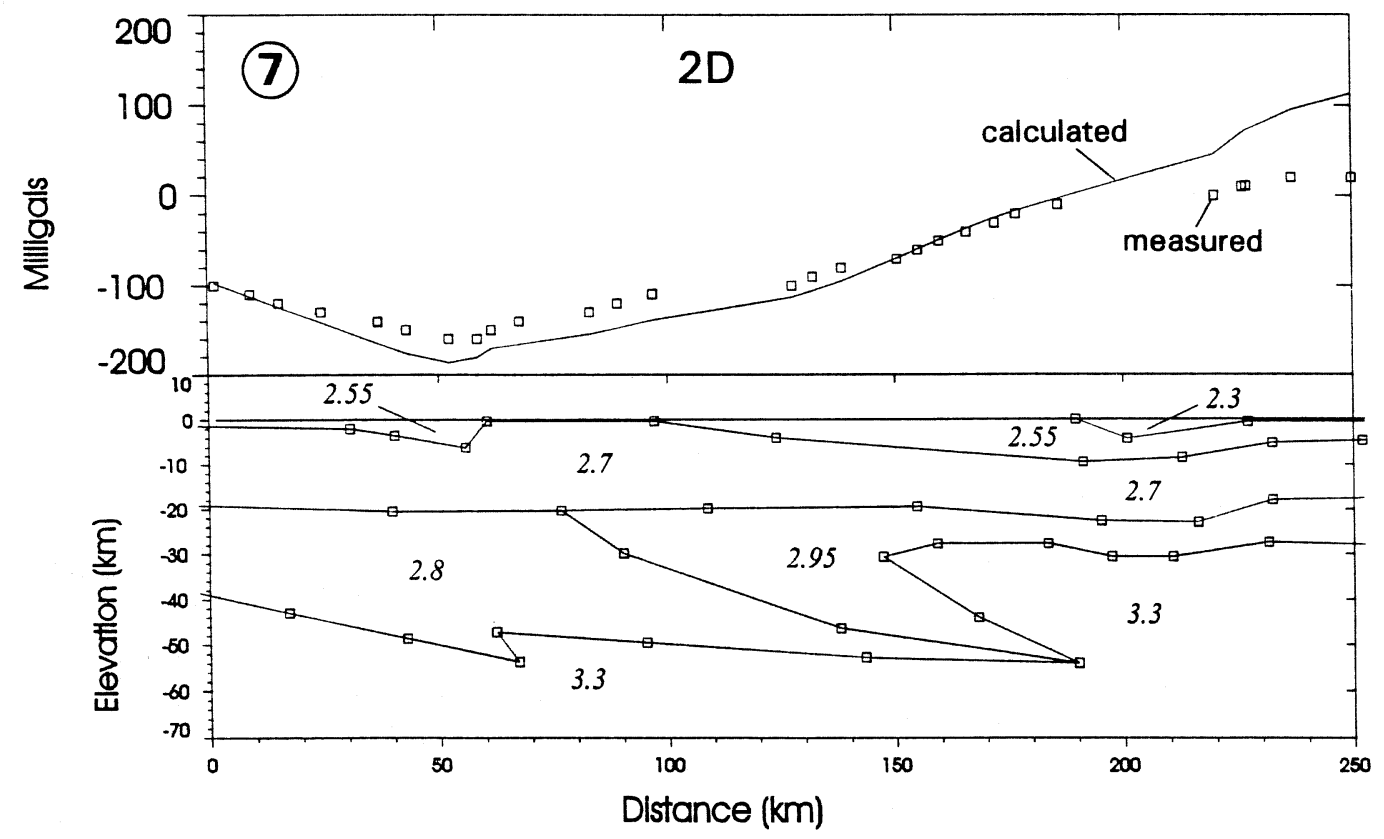

Fig. 4.2. $2 \mathrm{D}$ gravity model along cross section 7 . See fig. 3.7 for comparison with the $3 \mathrm{D}$ model. 
crust that protrudes northwards up to the southern boundary of the Tauern, thus enhancing the negative gradient.

As far as the shallow formations are concerned, the fitting of the model in this area also requires an uplift of the «crystalline crust» $\left(\delta=2.7 \mathrm{~g} \times \mathrm{cm}^{-3}\right)$ that tends to outcrop on both sides of the Pustertal line. These uplifts correspond to the Paleozoic and old crystalline rocks outcropping both in the southalpine and in the northalpine domains. The models of the easternmost cross-sections (11 and 12) are based on very poor seismic constraints. However, they clearly show a change of pattern due to the influence of the Dinaric and Adriatic domains. The thickness of low density overbur- den increases again. The negative anomaly in the area of the «Friulan Arc» is due to the sedimentary basin around Udine.

Figures 4.1 and 4.2 illustrate the results of the 2D modelling on cross sections 2 and 7 assuming the same geometry and density distribution used for the 3D modelling. The influence of lateral inhomogeneities both at shallow and at deep level is clear: in the 2D models the differences between the observed and calculated anomalies become unacceptable.

Figure 5 shows the map of the Bouguer anomalies calculated after the 3D modelling; the comparison with the measured anomalies of fig. 2 discloses the obtained good fitting.

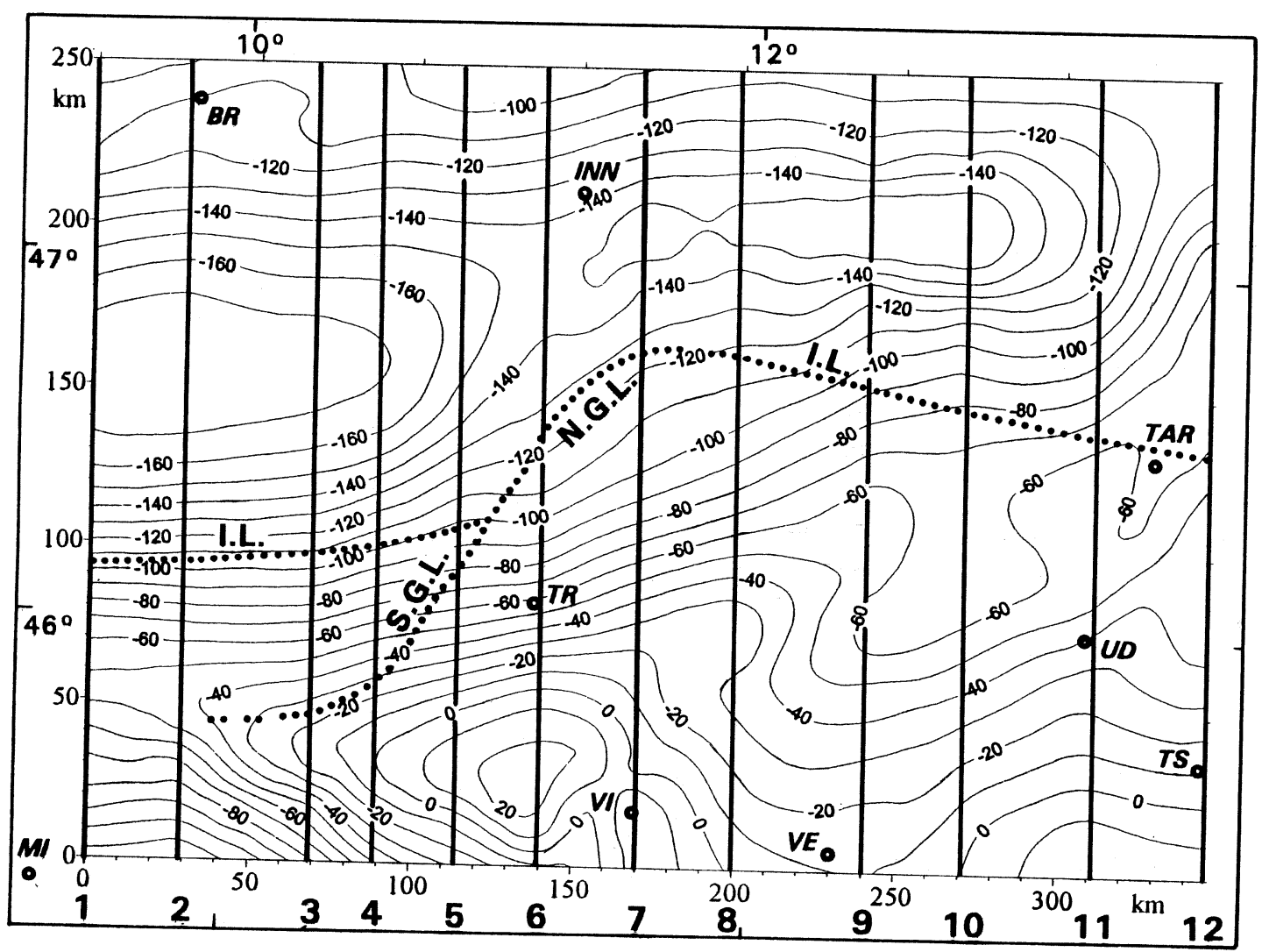

Fig. 5. Map of Bouguer anomalies calculated from the 3D modelling. Compare with fig. 2 . 


\section{Maps of Moho boundary and of interme- diate boundaries}

Figure 6 represents the Moho depth contour lines; this map is the same, with minor changes and simplifications, as the one obtained from the seismic interpretation, (Scarascia and Cassinis, 1997). The Moho depths resulting from the seismic interpretation have been assumed as constraints in the gravity modelling; therefore the comments on this map are the same as those summarized in the introduction. The main near vertical offsets of the boundary are also plotted with different symbols accord- ing to the interpreted height of the step. They correspond fairly well to the belts of strong gravity gradient. In some areas where the seismic data are missing, gravity modelling helps to interpolate the Moho pattern.

The depth contour lines of the top of the lower crust are plotted in fig. 7. They range from 18 up to $28 \mathrm{~km}$, the largest depths being reached in the southeastern sector of the study area. Also shown on the map is the northern limit of the lower crust with higher density $(\delta=2.95)$, which is assigned to the Adriatic domain, while the density of the European one is anomalously low (2.80). This limit protrudes

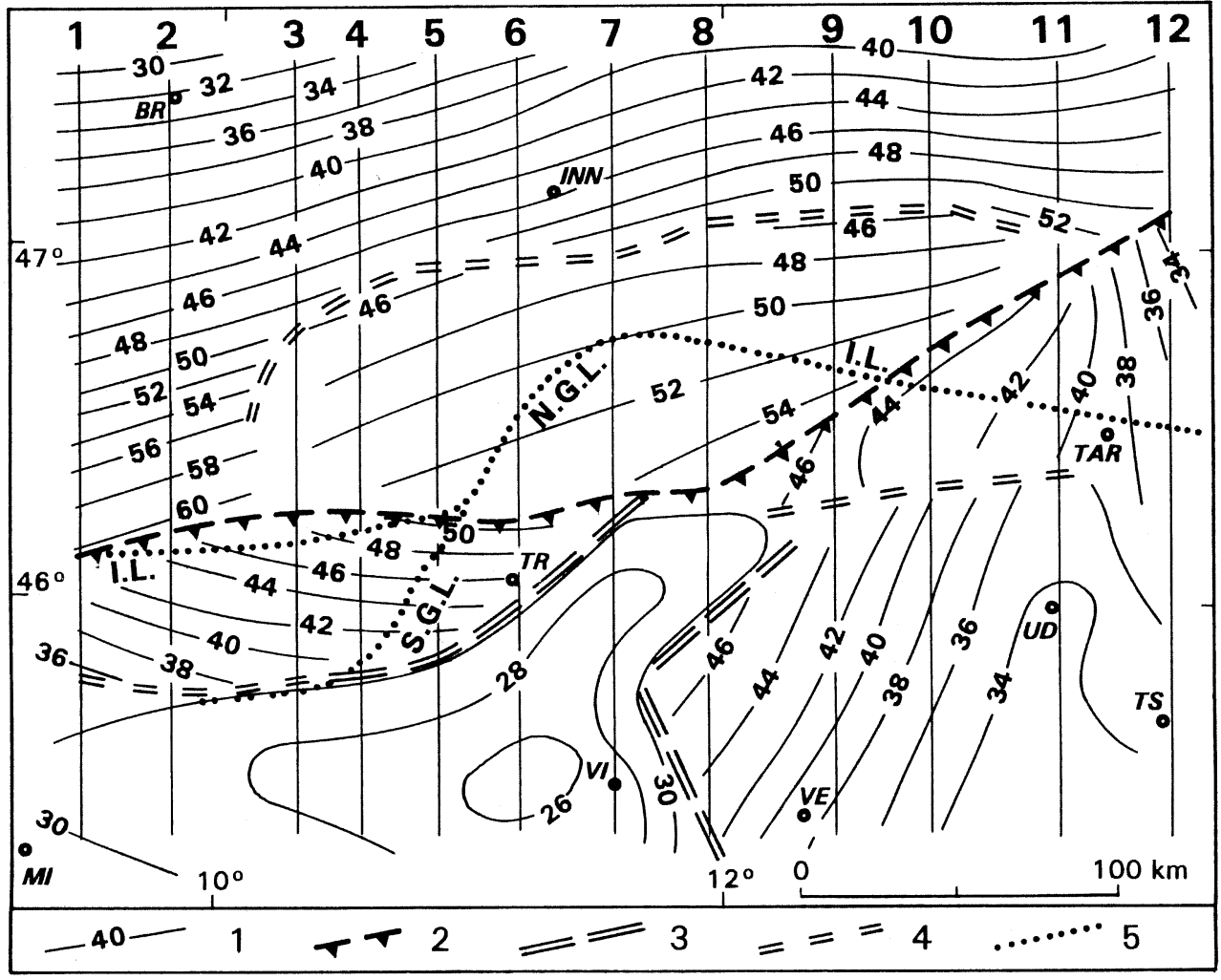

Fig. 6. Depth contour lines (1) of the Moho boundary $(\mathrm{km})$. The pattern of the Moho is derived, with minor changes, from the seismic interpretation by Scarascia and Cassinis (1997). The major near vertical offsets and overriding fronts are plotted. 2) Moho overriding front; 3) offsets $>10 \mathrm{~km}$; 4) offsets $<10 \mathrm{~km}$; 5) Insubric line. Note the good correspondence of the vertical offsets with the strips of high gravity gradient (see figs. 2 and 5). 


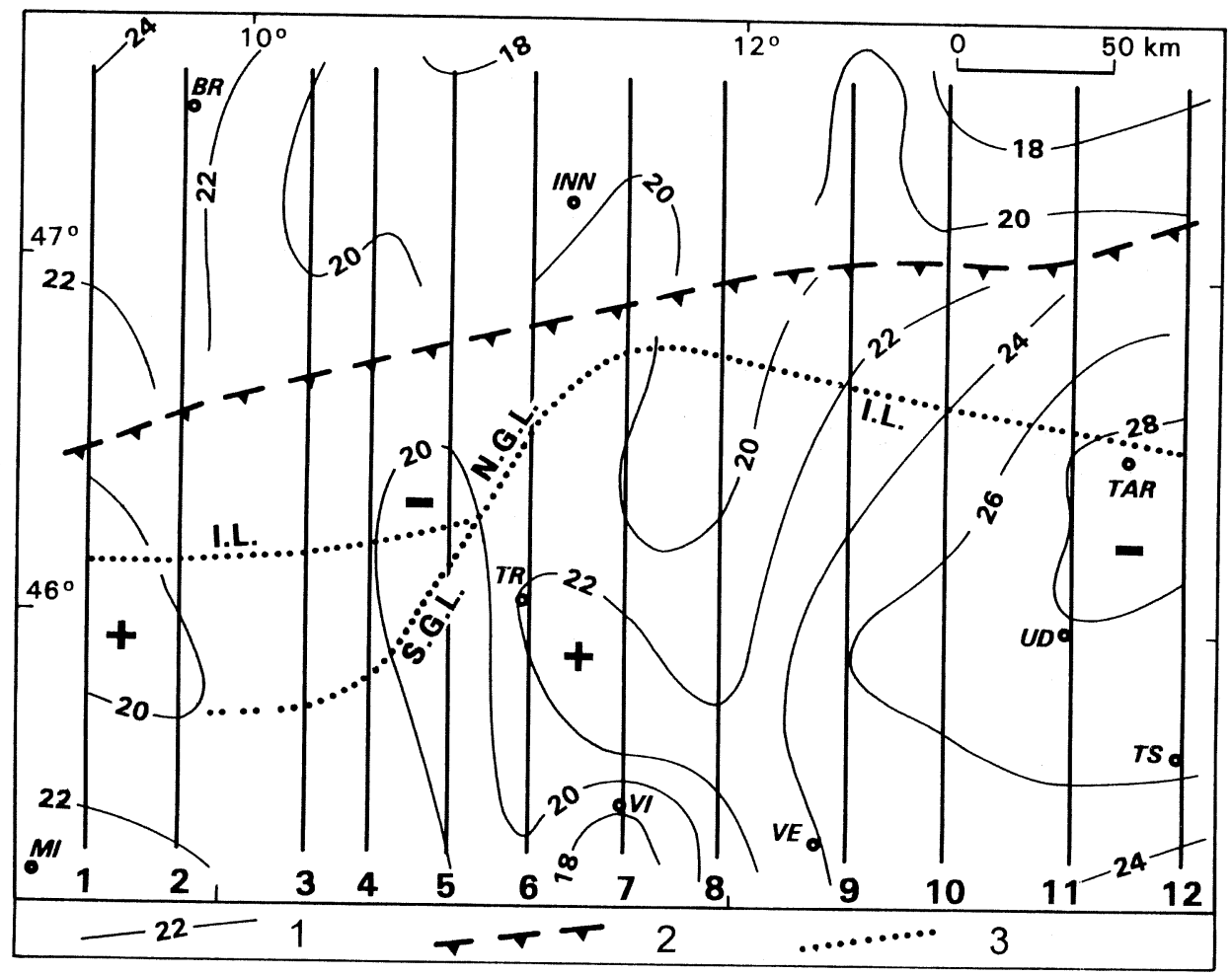

Fig. 7. Depth contour lines of the top of the lower crust $(\mathrm{km})$ as interpreted after the $3 \mathrm{D}$ modelling. The northern edge of the «Adriatic indenter» is shown, overriding the European lower crust. 1) Depth contour lines; 2) overriding front of the Adriatic lower crust; 3) Insubric line.

northwards, well beyond the edge of the Adriatic Moho, and may be considered as the front of the Adriatic lower crust overriding the European one.

It seems worthwhile to recall here another important result of the seismic study that is not contradicted by the gravity models: it concerns the relation between the present surface tectonic features and the deep structures. While the suture belt between the Adriatic and the European Moho corresponds to the Tonale line (western sector of the Insubric or Periadriatic lineament) up to the Giudicarie, after the intersection with this latter line it continues straight eastwards for about $50 \mathrm{~km}$, thus irrespective of the large shift northwards produced by the sinistral transform of the «Giudicarie phase»
(Laubscher, 1994). Further eastwards the Moho edge of the Adriatic plate bends northeastwards crossing again the eastern sector of the insubric lineament (Pustertal). Therefore it seems that, while in the Central Alpine sector the surface tectonic features correspond to the deeper ones, in the Eastern Alps they appear strongly disjointed. This would imply a different geotectonic regime.

Finally, fig. 8 shows the contour lines of the top of the formation with density $2.7 \mathrm{~g} \times \mathrm{cm}^{-3}$ that in a general sense, can be interpreted as the «crystalline upper crust». The pattern of the top of this body is derived from very few seismic constraints, from geological information and from the 3D modelling itself. The map outlines a wide zone in the NE sector of the 


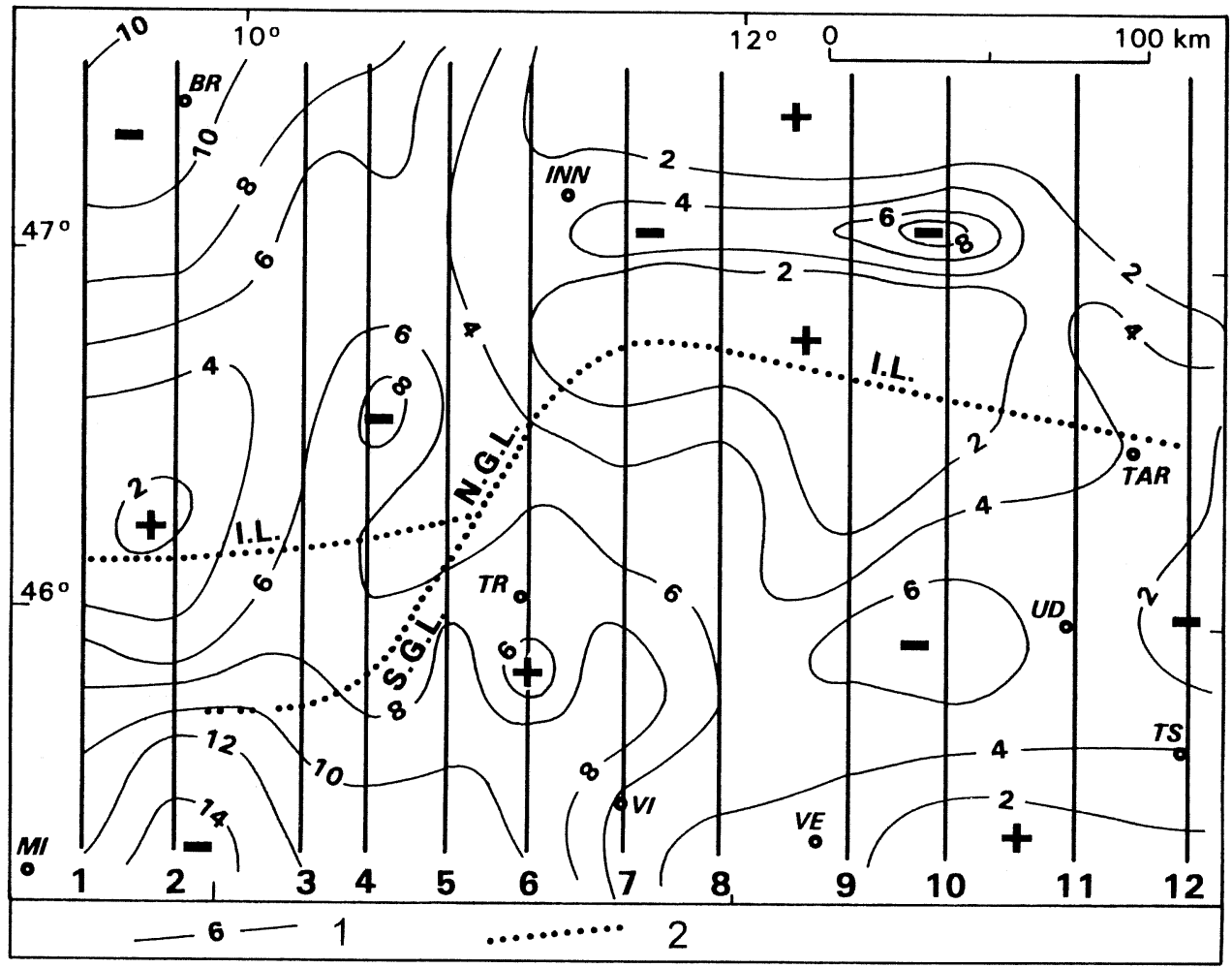

Fig. 8. Depth contour lines $(\mathrm{km})$ of the top of the body with density $2.7 \mathrm{~g} \times \mathrm{cm}^{-3}$, interpreted as the top of the crystalline upper crust. 1) Depth contour lines; 2) Insubric line.

study area where these denser layers are nearly outcropping. The largest thicknesses of the surface low density layers (up to $10 \mathrm{~km}$ ) are found in the southern sector. A relatively thin overburden is observed in a wide area on both sides of the Pustertal line, as well as along the Tonale line and in the southeastern zone, near Trieste and Istria. A larger thickness, up to about $8 \mathrm{~km}$, is found in a narrow strip along the Tauern window.

\section{Conclusions}

This study can be regarded as an implementation of the seismic interpretation. First of all it shows that the regional gravity anomalies do not contradict the seismic model of the deep crust and Moho boundary, taken as a reference.
Moreover 3D gravity modelling helps to define the structures in the intermediate and upper crust: the top of the lower crust and the position of the overriding front (Adriatic indenter) are better positioned. Also the top of the crystalline upper crust is detailed, yielding some information that could help to elucidate the tectonic evolution of the orogen.

\section{REFERENCES}

BAYER, R., R. LANZA, C. TRUFFERT, ECORS-CROP and ECORS (ALPES 2, JURA-BRESSE) gravity and magnetic group (1996): Gravimetric and magnetic studies of the Western Alps in the context of the ECORS and ECORS-CROP projects; data and interpretation, in The ECORS-CROP Alpine Seismic Traverse, Mémoires de la Societé Géologique de France, Nouvelle série, 1996, Mémoire, 170, 61-72. 
BERCHEMER, H. (1968): Topographie des «Ivrea Korpers» abgeleitet aus seismichen und gravimetischen Daten, Schweizerische Mineralogische und Petrographische Mitteilungen, 48, 235-246.

BuNESS, H. (1992): Krustale kollisionstructuren an den Ränden der Nordwestlichen Adriaplatte, Ph.D. Thesis, Freie Universität Berlin, pp. 221.

Cassano, E., I. Anelli, R. Fichera and V. Cappelli (1986): Pianura Padana: interpretazione integrata di dati geofisici e geologici, Agip, $73^{\circ}$ Congresso Soc. Geol. It., Roma, 1-27.

Castellarin, A., L. Cantelli, A.M. Fesce, J.L. Mercier, V. Picotti, G.A. Pini, G. Prosser and L. SELLI (1992): Alpine compressional tectonics in the Southern Alps. Relationships with the Northern Apennines, Ann. Tectonicae, 6 (1), 62-94.

Goetze, H.J. and B. LAHMEYER (1988): Application of three-dimensional interactive modelling in gravity and magnetics, Geophysics, 53 (8), 1096-1108.

Holliger, K. and E. KISSLING (1992): Gravity interpretation of a unified 2D acoustic image of the Central Alpine collision zone, Geophys. J. Int., 111, 213-225.

Italian Geological SuRvey (1989): Gravimetric Map of Italy, scale 1:1000000, 2 sheets, Istituto Poligrafico and Zecca dello Stato, Rome.

KARNER, G.D. and A.B. WATTS (1983): Gravity anomalies and flexure of the lithosphere at mountain ranges, J. Geophys. Res., 88, 10449-10477.

LAMMERER, B. (1996): Profil N-S von München nach
Bassano del Grappa, in Projektvorschlag Ostalpen Traverse, DEKORP Arbeitsgruppe Ostalpen, zusammengestellt VON H. GEBRANDE und M. BopP, München.

LAUBSCHER, H.P. (1994): Deep structure of the Central Alps in the light of recent seismic data, Geol. Rundsch., 83, 237-248.

NAFE, J. and C.L. DraKe (1963): Physical properties of marine sediments, in The Sea, edited by M.N. HILL (Interscience, New York, N.Y.), vol. 3, 794-815.

RÖEDER, D. and H. BoGEL (1978): Geodynamic interpretation of the Alps, in Alps, Apennines, Hellenides, edited by H. Closs, D. Roeder and K. SCHMidT, E. Schweitzerbart, Stuttgart.

SCARASCIA, S. and R. CASSINIS (1997): Crustal structures in the Central-Eastern Alpine sector: a revision of the available DSS data, Tectonophysics, 271 (1/2), 157-188.

SCHWEIZERISCHE GEOPHYSIKALISCHE KOMMISSION (1979): Schwerekarte der Schweiz, Bouguer Anomalien (Karte 4), scale 1:500000, Bundesamnt fuer Landestopographie, Wabern.

SENFTL, E. (1965): Schwerekarte von Oesterreich, Bundesamnt fuer Eich-und-Vermessungswesen, Vienna.

Ye, S., J. Ansorge, E. Kissling and St. Mueller (1995): Crustal structure beneath the Eastern Swiss Alps derived from seismic refraction data, Tectonophysics, 242, 199-221. 